\title{
Analytical and Experimental Studies on Active Suspension System of Light Passenger Vehicles
}

\author{
Waseem Hamid ${ }^{1}$, and Dharminder Kumar ${ }^{2}$ \\ ${ }^{1}$ M.Tech Scholar, Department of Electrical Engineering, RIMT University, Gobindgarh, Punjab, India \\ ${ }^{2}$ Professor, Department of Electrical Engineering, RIMT University, Gobindgarh, Punjab, India
}

Correspondence should be addressed to Waseem Hamid; showkat.tahir@gmail.com

Copyright ( 2022 Waseem Hamid et al. This is an open-access article distributed under the Creative Commons Attribution License, which permits unrestricted use, distribution, and reproduction in any medium, provided the original work is properly cited.

\begin{abstract}
The Automobiles have become a part of our everyday life. Since their common introduction and popularization in the 1910s. They have come a long way. Early vehicles did have a form of suspension which was borrowed from the horse carriages. This however proved to be too stiff for the vehicles powered by artificial engines, rather than horses. To counter this a lot of research was done pertaining to this subject and the result was the modern-day class of suspension systems, which are entirely passive and are either based on hydraulics based on oil, pneumatic based on air or simply spring type, or a combination of these. Lately the high-end vehicle segment introduced a technology of active suspension, rather than passive one. This design uses sensors to determine road contours to determine the action the suspension should take so that the vehicle experiences least acceleration vertically and laterally, also known as a bump. This work analyses a simple active suspension system.
\end{abstract}

KEYWORDS: Suspension System, Passenger Vehicle, Hydraulics, Simulink.

\section{INTRODUCTION}

When a vehicle is driving, road performance has an important impact on comfort and stability[1]. The chassis is an important component, which plays a vital role in the power transmission between the tire and the body, and reduces the impact on the road. Therefore, maintaining the road surface roughness at the front of the vehicle to control its suspension and improve driving comfort and driving stability has attracted the attention of researchers. Current active suspension systems only modify its parameters when the road changes texture [2]. Using a sensor system to determine the road the vehicle is driving on, and using builtin controls to process relevant data can maximize its potential. Therefore, previewing the suspension system is essential for future landing gear.

An active suspension system can be coupled with filtering to make the vehicle move independent of road contact position, so that any bump in the road is handled by the suspension and the vehicle is also adjusted so as to remove any undesirable acceleration from the main body. The inner control loop for road compensation and the outer control loop for chassis movement are blended together and demonstrated in the simulation.

\section{RELATED WORK}

A suspension system with proper cushioning Every car travelling on a haphazardly shaped road is subjected to tremors that are damaging to both the passengers' enjoyment and the vehicle's longevity. As a result, the primary function of suspension system is to provide passenger comfort and road hold under a range of roadways and automotive manoeuvres. This, in turn, would have a clear impact on safety. A decent mattress should, in general, give a pleasant ride and adequate performance within a suitable displacement range. Furthermore, these criteria are arbitrary and are based on the vehicle's intended use. As a result, it is critical in a proper suspension systems to fairly decrease the perturbation to the inputs (e.g. vehicle height, etc.). It must be "soft" when it comes to road interruptions and "hard" when it comes to overloads. A car with a severely damped suspensions will have outstanding steering, but it will also transfer a lot of road input to the vehicle body. As a result, damper design is an art of balancing these two objectives. A decent passive control design can help with optimal riding experience and road holding abilities to some extent, but it can't totally eliminate the tradeoff. This topic was covered in a number of publications and papers.,

M. Leegwater This maximises the car's twisting velocity, according to calculations utilising a full-car model. The traction control technology promotes safety since intense cornering may be necessary to stay on the road or avoid an impediment. The main cable springs may be modified only for convenience and road holding, while the active element of the foundation is responsible for achieving appropriate steering behaviour and static load changes.. Potential contribution that the energy needed to level the automobile during cornering is low, leading to the conclusion that the active suspension system can level the car inexpensively, [3]. The creation of an active suspension adjustment of a one-wheel automobile model utilising fuzzy intelligence and a disturbances observer was given by Yoshimura T. et al.(2005). 


\section{International Journal of Innovative Research In Engineering \& Management (IJIREM)}

\section{OBJECTIVE}

The objective of this project is to simulate an active suspension system implementation scheme for a light motor passenger vehicle.

\section{DESIGN AND METHODOLOGY}

Active springs are a term used to describe some of the most modern adaptive suspension systems. These are those who are driven by double-acting piston rod or solenoids (often referred to as actuators) installed at each wheel. To carry the vehicle's weight while keeping the proper body attitudes, each actuation establishes a form of hydraulic balance with the others;[4]. At the same time, each hydraulic actuator acts as its own isolator, obviating the necessity with yet another stabilization part. In other words, each servo serves both as a springy (with variable-rate cooling performance) and a steering damper (with changeable vibration characteristics). In a vehicle suspension system, this is achieved by adjusting the water pressure within every piston as well as the pace with which it raises or lowers. Each wheel may react individually to changing driving conditions either removing or removing hydrostatic fluid to the separate motors.

This process of bleeding can be controlled using a pump and reservoir system. The pump has to be able to draw the hydraulic damping fluid from the piston of the suspension, and also be able to pump it back into it, to maintain the pressure. The response time for the pump also has to be very fast. Due to this reason the cost of the pump is very high and thus for the whole active suspension system. This is the reason we do not often see passenger vehicles or domestic segment vehicles not having active suspensions[5]. There is also the constrain of control. The controller has to be able to respond fast to the sensor data and generate appropriate control signals. The sensors themselves are also a very important component. They need to scan the road surface and determine the bumps and the time it would take the vehicle to reach them at the current speed and then send this to the controller. The controller then generates a delayed command to the pump for the suspension piston. Which has to increase or decrease pressure corresponding to a pit or a bump respectively. This works as the vehicle tire encounters a pit, normally it would cause vehicle to lean towards that tire. This is what the system it trying to avoid, the increased pressure in the actuating piston at the correct time forces tire just the right amount into the contour of the pit. The pressure is varied such that the piston actuation is in line with the pit contour and the vehicle remains level, without any major vertical or lateral accelerations or jerks to the passenger(s). The same thing happens with the bumps, but in that case the pressure is decreased.

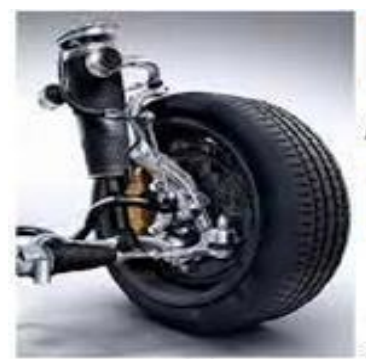

(a)

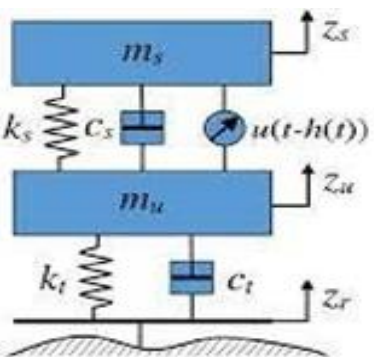

(b)
Figure 1: Mechanism

1) The above figure shows a real-world active suspension piston along with connected tire and axle shaft.

2) On the right the same system is denoted mathematically. $\mathrm{M}_{\mathrm{s}}$ denotes the mass of vehicle body handled by this type, ks denotes the spring constant for the spring coiled around the piston, which damps out smaller bumps easily. Cs is the response constant for the static behaviors of the piston, without any active control. u denotes the delayed unit step input of the active suspension system, whose adjusted response is $h(t)$. It is delayed because the wheel has yet to reach the area scanned by the sensors. $\mathrm{Kt}$ and $\mathrm{Ct}$ denote the spring constant and coefficient for the tire, since rubber has these properties inherently and especially for an air-filled tire.

Also, the $\mathrm{Zs}, \mathrm{Zu}$ and $\mathrm{Zr}$ are displacements for body, suspension and tire.

To reduce the cost of the suspension system, the efficiency of motor needs to be high for the oil pump. This will also be a factor for production at scale which will help reduce the cost of the suspension for the passenger vehicles.

Now the Simulation is performed in MATLAB by making a mathematical model for this suspension type[6]. The simulation performed in this case is script based, and utilizes a control system model constructed for the figure shown below, which is a stripped-down version of the model shown beside the tire earlier, to keep the design simple. Here tire constant $\mathrm{Ct}$ is removed and absorbed into tire spring constant $\mathrm{kt}$.

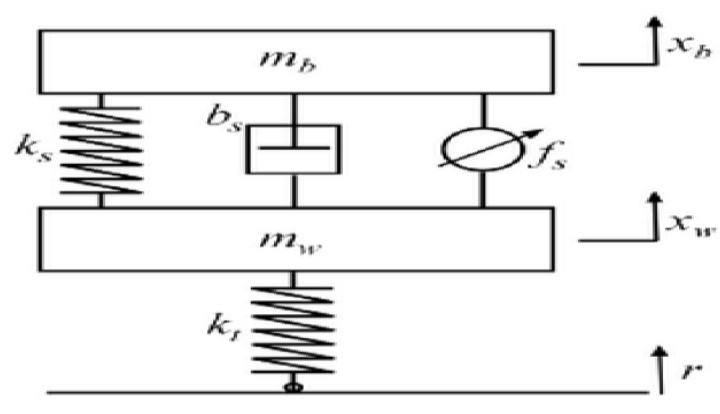

Figure 2: Simulation Model

The displacements are now labelled as $\mathrm{xh}$ for body, $\mathrm{xw}$ for wheel-suspension assembly and $\mathrm{r}$ is the variation in road height (irregularities in road or bumps and pits).

The mass of vehicle body is mb and mass of wheel assembly is mw, $\mathrm{kt}$ is the tire spring constant and ks is the spring constant for suspension (spring coil), bs is the 


\section{International Journal of Innovative Research In Engineering \& Management (IJIREM)}

natural spring constant for hydraulic damper and fs is the active suspension input to the suspension assembly[7].

\section{A. State Space Equations}

Note that there are 2 energy storage elements, the vehicle body with its weight and momentum, and passive damping from the hydraulic part.

$$
\begin{aligned}
&\left(x_{1}, x_{2}, x_{3}, x_{4}\right):=\left(x_{b}, \dot{x}_{b}, x_{2 w}, \dot{x}_{w}\right) \\
& \dot{x}_{1}=x_{2} \\
& \dot{x_{2}}=-\left(1 / m_{b}\right)\left[k_{s}\left(x_{1}-x_{3}\right)+b_{s}\left(x_{2}-x_{4}\right)-f_{s}\right] \\
& \dot{x_{3}}=x_{4} \\
& \dot{x_{4}}=\left(1 / m_{w}\right)\left[k_{s}\left(x_{1}-x_{3}\right)+b_{s}\left(x_{2}-x_{4}\right)-k_{t}\left(x_{3}-r\right)-f_{s}\right] .
\end{aligned}
$$

Now to construct this model in MATLAB, a new .m or matlab script file is created. First, we enter the constant values;

$$
\begin{aligned}
& m b=300 ; \quad 9 k g \\
& \mathrm{~mW}=605 \quad 9 \mathrm{~kg} \\
& \mathrm{bs}=1000 ; \quad \text { g } \mathrm{N} / \mathrm{m} / \mathrm{s} \\
& k s=16000 ; g \mathrm{~N} / \mathrm{m} \\
& \mathrm{kt}=190009 ; \quad \mathrm{N} / \mathrm{m}
\end{aligned}
$$

th the actual value since we are studying for a single Note that the vehicle body mass $\mathrm{mb}$ is $1 / 4$ tire. Also in real world scenario the tires beside the engine carry more weight, this is not considered here. The weight is considered to be uniformly distributed over 4 wheels. Now form the state space matrices according to the equations for the model and the defined constant values;

$$
\begin{aligned}
& A=\left[\begin{array}{lllllllll}
0 & 1 & 0 & 0 ; & 0 & -k s & -b s & k s & b s
\end{array}\right] / m b ; \ldots \\
& \begin{array}{lllll}
0 & 0 & 0 & 1 ;
\end{array} \text { [ks bs -ks-kt -bs]/mw]; } \\
& B=[00 ; 010000 / \mathrm{mb} ; 00 ;[\mathrm{kt}-10000] / \mathrm{mw}] \text {; } \\
& C=[1000 ; 10-10 ; A(2,:)] \text {; } \\
& D=[00 ; 00 ; B(2,:)] \text {; }
\end{aligned}
$$

Now the model for the car can be constructed using ss command;

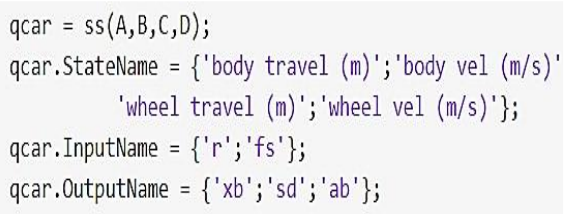

The model for the vehicle is now named as 'qcar' and the properties for its matrices are labelled using the commands, StateName, InputName and OutputName.

The natural tires systems have a resonant frequency where the wheel may experience vibration and it is called "hopping frequency for tire". In this case this value is 56.7 radians per second. At this frequency the transfer function has a zero and we need to declare it as follows; [8]

This gives the following output;

$$
\operatorname{tzero}\left(q \operatorname{car}\left(\left\{{ }^{\prime} x b^{\prime},,^{\prime} a b^{\prime}\right\},,^{\prime} f s^{\prime}\right)\right)
$$

Another resonant component is seen in the transfer function relating displacements for suspension and tire, in this case leading to a zero instead;

It is also obtained in a similar fashion as follows;

$$
\text { zero(qcar('sd', 'fs')) }
$$

Giving the result as;

$$
\begin{aligned}
& \text { ans = } \\
& 0.0000+22.9734 i \\
& 0.0000-22.9734 i
\end{aligned}
$$

Thus, the zero occurs at 22.9 radians/second Now to observe the behavior of accelerations due to vehicle bulk, suspension passive and active parts as well as road irregularities:

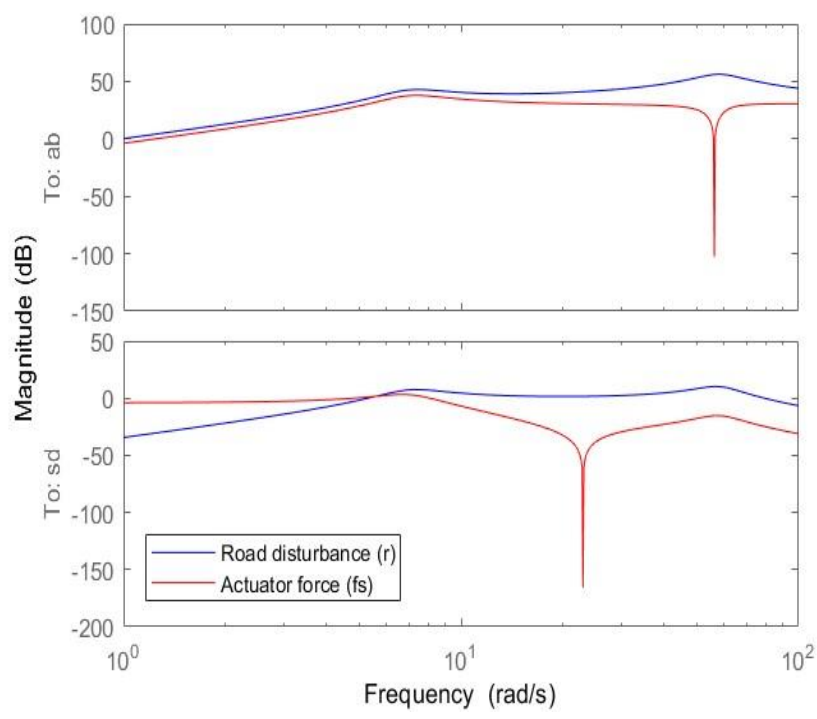

Figure 3: Bode Response

The above output was obtained using the body command, note the dip due to pole as we calculated earlier. Now to model the active suspension system we use the following transfer function; The transfer function is of order $1 ; 1 /$ (1 $+\mathrm{s} / 60)$

This function is however restricted for lower frequency region and for higher increasing frequencies shows increasingly large errors. To counter this the tf is multiplied with a weight matrix such that at known points of frequency and error, appropriate correcting scale factor brings the model within justified limits of accuracy, the above shows 0.4 error for 3 radians and this keeps on increasing to around 2 at 15 radians. The following shows the corrections applied:[13]

Wunc $=$ makeweight $(0.40,15,3)$;

unc = ultidyn('unc', [1 1], 'SampleStateDim' , 5);

Act $=\operatorname{ActNom} *\left(1+\right.$ Wunc $^{*}$ unc $)$;

Act. InputName = ' $u$ ';

Act. OutputName = ' $f s^{\prime}$;

The bode response for this is now based on the variable Act (short for the actuator here) 


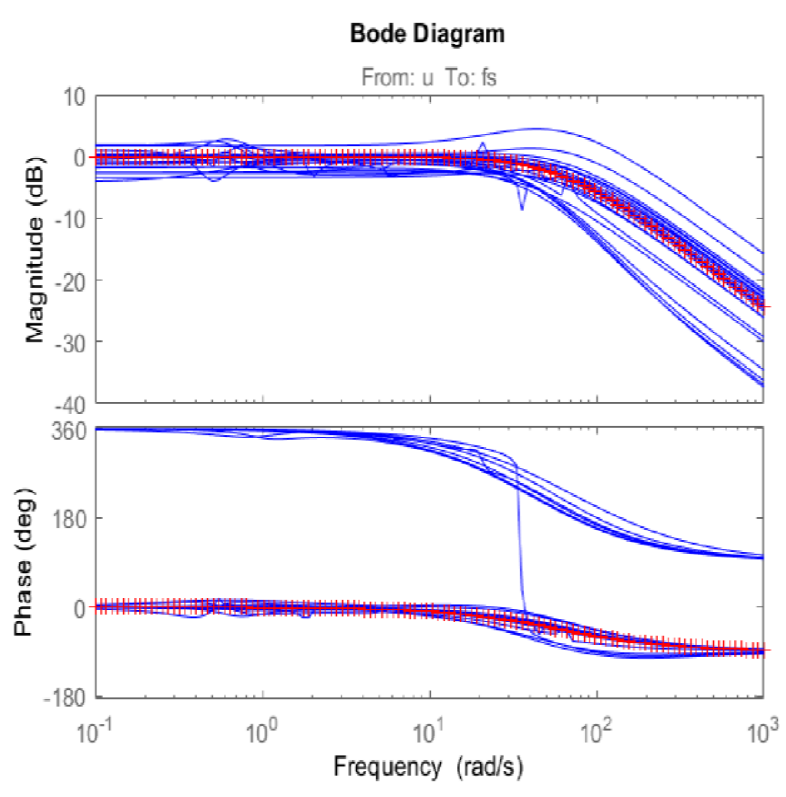

Figure 4: Bode Response

Now to combine the vehicle state space model with the suspension transfer function.

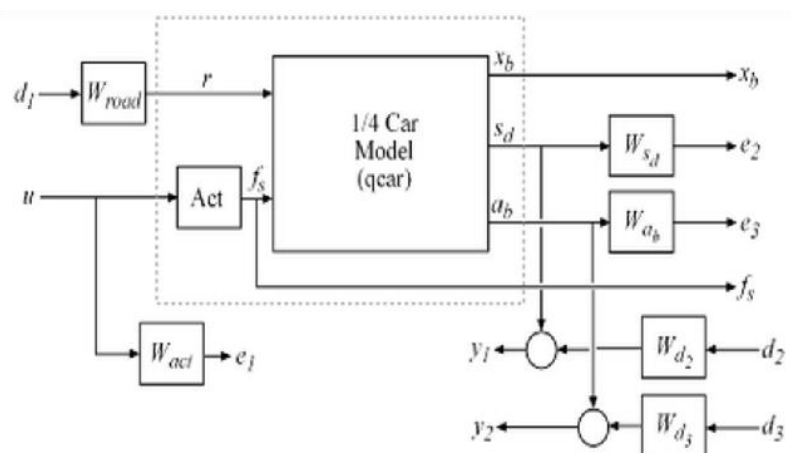

Figure 5: State Space Model Combined with Suspension Transfer Function

Here Wroad is a weight function taken as 0.7. This is here so that the "bumpiness" of the road can be easily varied in the simulation.di is the normalized value for the processed signals. Similarly for varying road conditions we can use a weight varying matrix for Wroad[10];

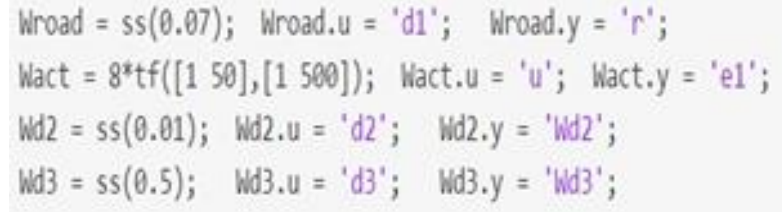

Also, ei are error signals. The block labelled Act in the diagram earlier is also a weight for the type of hydraulic piston and can also be varied by setting value for Wact. We again plot the response in form of bode plot, since It allows for instant data interpretation over wide range of possible inputs. The output obtained in this case is as follows:

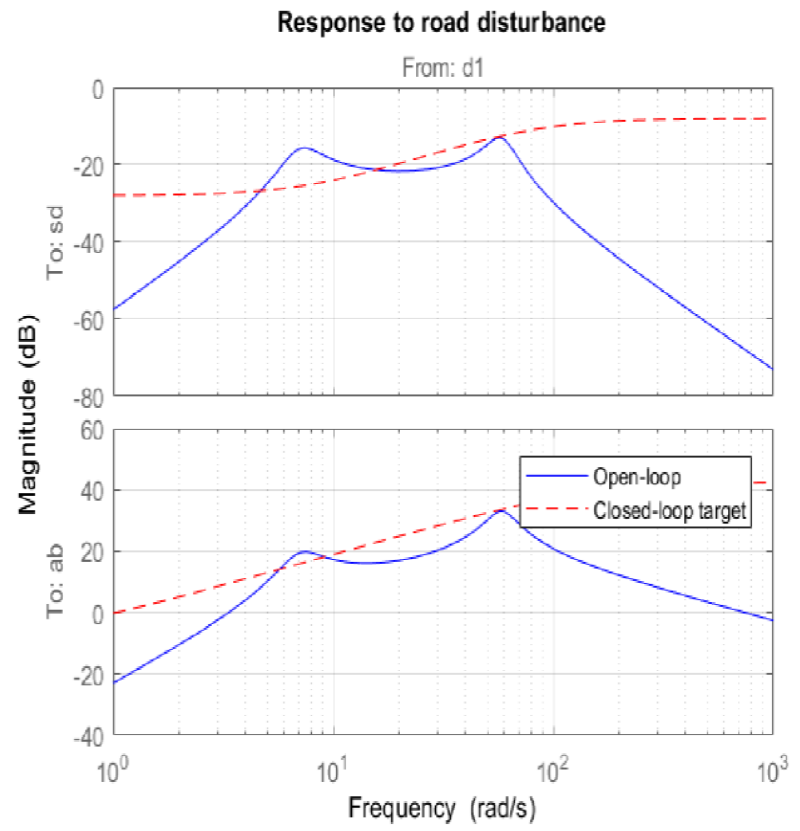

Figure 6: Bode Response

As can be noted the blue curve shows the irregularities in road by frequency, and the response of open-loop or passive suspension, is fairly similar to input, i.e., most of the vibrations and jerks go undamped shaking the passengers in the vehicle, possibly causing discomfort and handling issues. In comparison, the closed loop response shows a smooth curve where the vehicle shows displacement, but that is spread over time such that it goes unnoticed by passenger to a significant degree improving experience and control [9].

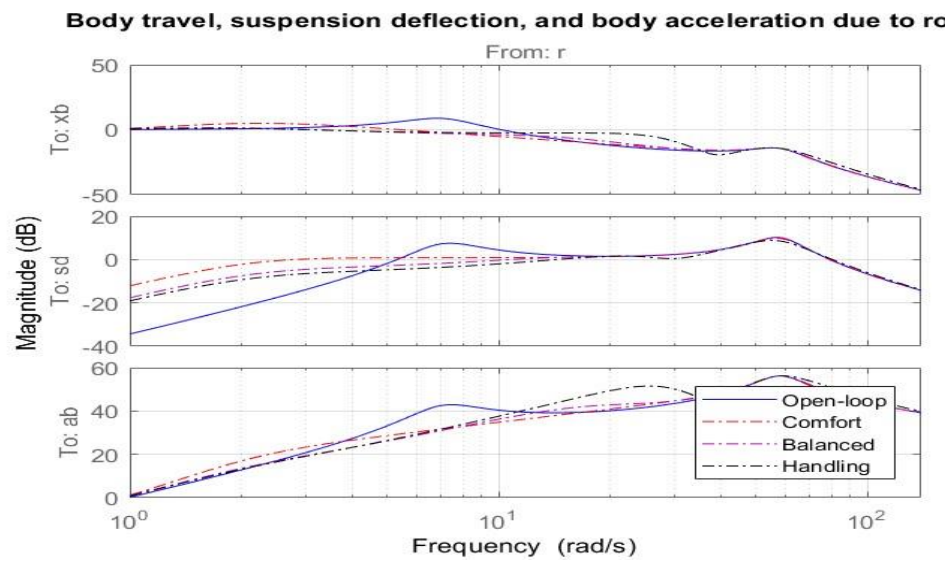

Figure 7: Bode Response 
The same can be analyzed in time domain as well for a more visual approach. Below is the brief code and responses so obtained:
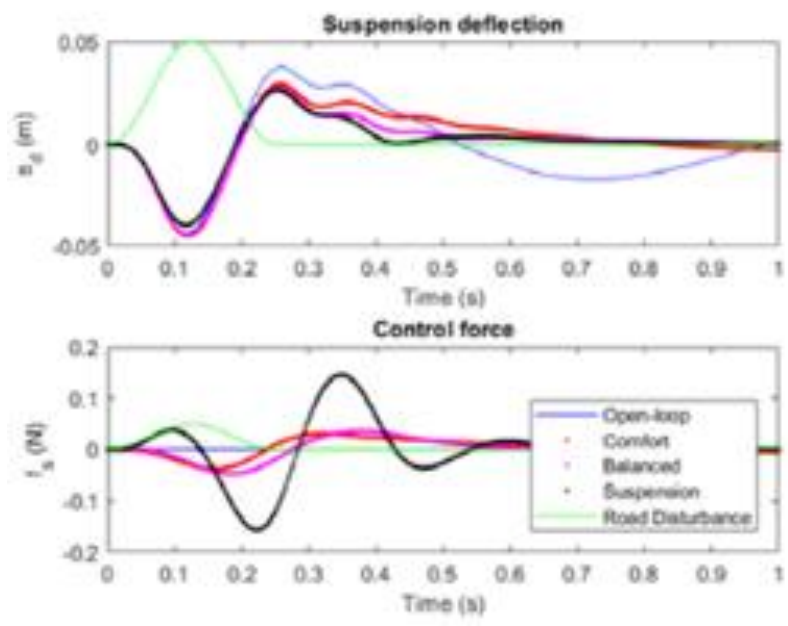

Figure 8: Open Loop Bode Response

This is open loop and the jerks are obvious. See the closed loop for comparison below. The closed loop here is implemented using robust control design [11]:
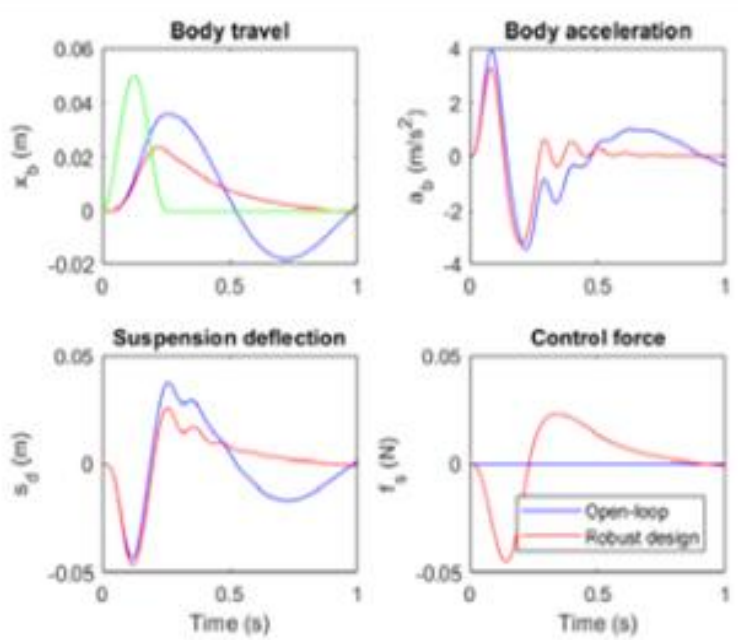

Figure 9: Closed Loop Bode Response

Note the closed loop response is very smooth and has lower travel pertaining to the irregularities of road and any induced accelerations and displacements [12] The response for multiple bumps over time and the averaged response of vehicle suspension system:

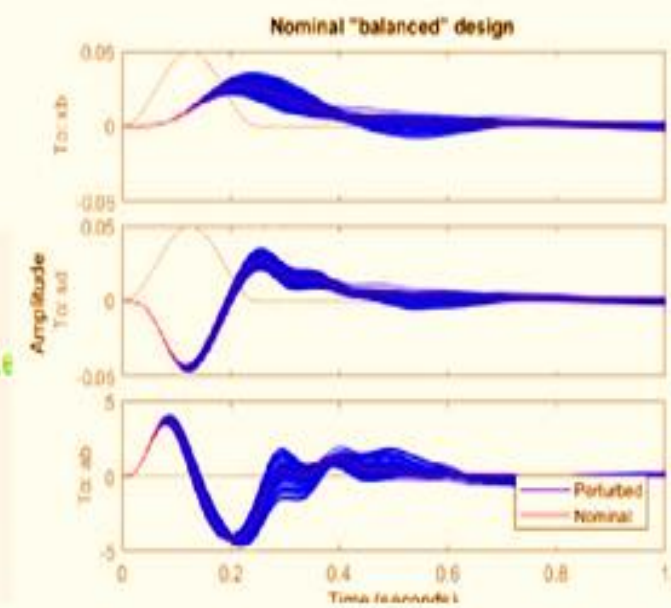

Figure 10: Multiple Bump Bode Response

\section{CONCLUSION}

To conclude, the results obtained in this work satisfied the criteria of improving user experience in a passenger vehicle. The suspension system, in this case handed most of the complexity to digital control, which brings the cost significantly down, thus making the design viable for passenger vehicles. The response of the closed loop system also was very good in comparison to open-loop and just standalone spring suspension system.

\section{CONFLICTS OF INTEREST}

The authors declare that they have no conflicts of interest.

\section{REFERENCES}

[1] C. Richard, R. Dorf -, 2005. "Modern Control Systems", Pearson Prentice Hall.
[2] E. Jack, 2008. "Automotive Technology", A Systems Approach, Delmar, Cengage Learning.

[3] E. James Duffy, 2000 "Modern auto mechanics", the Good Heart well-willcox company, Inc. Publisher. [4] G. Giancarlo, M. Lorenzo 2005. "The Automotive Chassis", Vol.1:Components Design ,Mechanical Engineering Series, Springer .

[4] H. Julian, 2004. "An Introduction to Modern Vehicle Design", ButterworthHeinemann .

[5] I. Dogan, 1998. "Microcontroller Based Applied Digital Control", John Wiley \& Sons Ltd .

[6] M. Galal Rabie, Ph.D."Fluid Power Engineering", Copyright $\odot 2009$ by The McGraw-Hill Companies.

[7] M. S. Leegwater, 2007, An active suspension system, $\mathrm{PhD}$ thesis, Eindhoven university of technology. September 2007. [9] Parker, 2003. Servo valves Series BD, PH and SE Catalogue HY11-3292/UK, November 2003.

[8] S. Mouleeswaran, 2008. Development of Active Suspension System for Automobiles using PID Controller, 
Proceedings of the World Congress on Engineering 2008 Vol II WCE 2008, July 2 - 4, 2008, London, U.K.

[9] S. R. Burns, 2007. "Advanced Control Engineering", Professor of control engineering, Department of mechanical and marine engineering, university of Plymouth, UK

[10]. Dhananjay Rao, Modeling, Simulation and Control of Semi Active Suspension System for Automobiles under MATLAB Simulink using PID Controller, IFAC Proceedings Volumes, Volume 47, Issue 1, 2014, Pages 827-831, ISSN 1474-6670, ISBN9783902823601.

[11] Herran,L.C.F.,Ortiz,J.D.J.R.,Soto,R.and Mendoza, R. R (2008) Modelling and Control for a semi active Suspension with a Magneto-rheological Damper including the actuator dynamics, IEEE Computer society, Electronics, Robotics and Automotive Mechanics Conference, 338- 343, California.

[12] Kumar,M.S.(2008) Development of Active System for Automobiles using PID Controller, world Congress on Engineering, 2 , London ,U.K. 